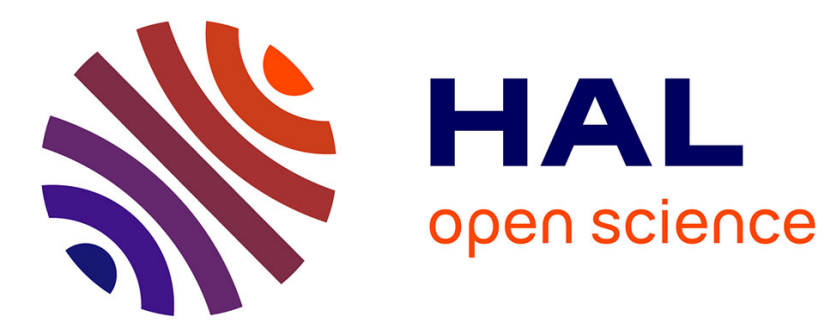

\title{
Improvement of power supply electromagnetic compatibility by extension of chaos anti-control
}

Cristina Morel, Marc Bourcerie, François Chapeau-Blondeau

\section{To cite this version:}

Cristina Morel, Marc Bourcerie, François Chapeau-Blondeau. Improvement of power supply electromagnetic compatibility by extension of chaos anti-control. Journal of Circuits, Systems, and Computers, 2005, 14, pp.757-770. 10.1142/S0218126605002556 . hal-01202806

\section{HAL Id: hal-01202806 \\ https://hal.science/hal-01202806}

Submitted on 7 Mar 2018

HAL is a multi-disciplinary open access archive for the deposit and dissemination of scientific research documents, whether they are published or not. The documents may come from teaching and research institutions in France or abroad, or from public or private research centers.
L'archive ouverte pluridisciplinaire HAL, est destinée au dépôt et à la diffusion de documents scientifiques de niveau recherche, publiés ou non, émanant des établissements d'enseignement et de recherche français ou étrangers, des laboratoires publics ou privés. 


\title{
IMPROVEMENT OF POWER SUPPLY ELECTROMAGNETIC COMPATIBILITY BY EXTENSION OF CHAOS ANTICONTROL
}

\author{
CRISTINA MOREL*, MARC BOURCERIE and FRANÇOIS CHAPEAU-BLONDEAU \\ Laboratoire d'Ingénierie des Systèmes Automatisés (LISA), Université d'Angers, \\ 62 avenue Notre Dame du Lac, 49000 Angers, France \\ *Cristina.Morel@univ-angers.fr
}

\begin{abstract}
Switch-mode power supplies usually emit electromagnetic interferences at the switching frequency and its harmonics. Inducing chaos in these systems has recently been suggested as a means of reducing these spectral emissions, yet at the expense of aggravating the overall magnitude of the ripple in the output voltage. We propose here a new nonlinear feedback control method, which induces chaos, and which is able at the same time to achieve low spectral emission and to maintain a small ripple in the output. The feasibility and usefulness of this new and simple method is shown here with a numerical example, which includes a comparison with the previous control method.
\end{abstract}

Keywords: Anticontrol of chaos; Buck converter; power spectrum; output voltage ripple.

\section{Introduction}

DC-DC converters are some of the most widely used circuits in power electronics. ${ }^{1,2}$ They are usually used in situations where there is the need of stabilizing a given input DC voltage to a higher (Boost), a lower (Buck) or a generic (Buck-Boost) output voltage. ${ }^{3}$ This is generally achieved by chopping and filtering the input voltage through an appropriate switching action, mostly implemented via a pulse width modulation.

Switch-mode power supplies generate electromagnetic interference at the switching frequency and its harmonics. Interference emission create significant electromagnetic compatibility difficulties ${ }^{4}$ especially when high currents or high voltages are switched rapidly. The reduction of power supply emissions can be achieved through various methods that modulate the switching frequency, a technique that reduces spectral emissions. ${ }^{5,6}$

The work of Ref. 4 presents the idea that chaos, a phenomenon which can naturally occur in switch-mode power supplies, might be used to improve their electromagnetic compatibility by reducing spectral peaks. The benefit of this kind of chaotic operation is the reduction of the electromagnetic interference; this advantage 
is unfortunately counterbalanced by the increase of the ripple (the peak to peak output voltage). ${ }^{7,8}$

The task of intentionally creating chaos (a transition between order to chaos) sometimes called chaotification or anticontrol of chaos - has attracted a lot of attention in recent years due to its great potential in nontraditional applications for physical, electrical, optical, mechanical, chemical, biological, and medical systems. ${ }^{9,10}$

The anticontrol reference method designs a simple nonlinear feedback controller with an arbitrarily small amplitude ${ }^{11-13}$ obtaining chaotic dynamics in the controlled system. The application of the classical method ${ }^{11,12}$ of chaos anticontrol to switch-mode power supplies reduces the output voltage spectral emissions, but aggravates the overall magnitude of the ripple. ${ }^{14}$

The purpose of this paper is to introduce a method of chaos generation in switching systems in general and power electronic circuits in particular to reduce the electromagnetic interferences at the switching frequency and its harmonics.

Therefore, we use here a new nonlinear feedback controller and show that it maintains a small ripple in the output and is able at the same time to achieve a low spectral emission. Finally, the combination of this feedback controller with the standard anticontrol method reduces even more the power contained in the spectral peaks, without deteriorating the output voltage ripple. Indeed, applying chaos anticontrol to switch-mode power supplies improves the performance both in the frequency-domain (spectrum) and in the time-domain (ripple). The feasibility and usefulness of this new and simple method is shown here with a numerical example, which includes a comparison with the classical anticontrol method.

\section{The Buck Converter}

Figure 1 shows the diagram of a Buck converter that uses a pulse width modulated voltage loop. ${ }^{15}$ The circuit has two states determined by the position of the switch $S$. When $S$ is closed, the input voltage $E$ provides energy to the load $R$ as well as to the inductor $L$. When $S$ is open, the inductor current $i$, which flows through diode $D$, transfers some of its stored energy to the load $R$. The amplifier $A_{2}$ has a gain $a$. The simplest feedback converter is obtained when the switch $P$ in the zero position. The control law $v_{c}(t)$ can then be written as

$$
v_{c}(t)=v_{c 0}(t)=u_{1}(t)=a\left(v(t)-V_{\mathrm{ref}}\right) .
$$

The control law $v_{c}(t)$ is applied to the inverting input of the comparator $A_{1}$. The noninverting input is connected to an independent voltage ramp generator: its output voltage periodically rises from a low voltage $V_{L}$ to an upper voltage $V_{U}$ in a time $T$, and then instantaneously returns to $V_{L}$. This ramp voltage $v_{r}(t)$ can be expressed as

$$
v_{r}(t)=V_{L}+\left(V_{U}-V_{L}\right) \frac{t \bmod T}{T} .
$$




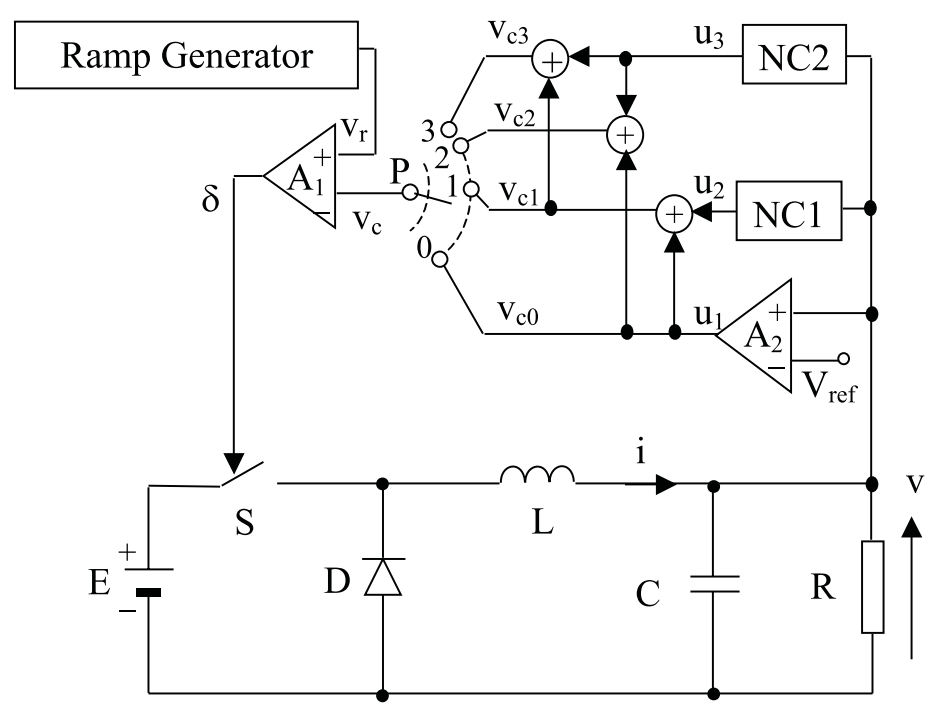

Fig. 1. DC-DC Buck converter with feedback controls. The values of the fixed parameters are taken from Refs. 2 and 15: $L=20 \mathrm{mH}, C=47 \mu \mathrm{F}, R=22 \Omega, a=8.4, V_{\text {ref }}=11.3 \mathrm{~V}, V_{L}=3.8 \mathrm{~V}$, $V_{U}=8.2 \mathrm{~V}, T=400 \mu \mathrm{s}$ and $E=16 \mathrm{~V}$.

When $v_{c}(t) \geq v_{r}(t)$, the switch $S$ is open and diode $D$ conducts; otherwise $S$ is closed and $D$ is blocked. The system is governed by two sets of linear differential equations that correspond to the on and off states of the controlled switch. The Buck converter is a second-order system since it has two energy storage elements. The voltage $v$ of the capacitor $C$ and the inductance current $i$ are chosen as state variables. ${ }^{2,16}$

The model of the converter can be written as

$$
\begin{aligned}
& \frac{d v}{d t}=\frac{1}{C} i(t)-\frac{1}{R C} v(t), \\
& \frac{d i}{d t}=-\frac{1}{L} v(t)+\frac{E}{L} \delta(t),
\end{aligned}
$$

where $E$ is a constant input voltage, and $\delta(t)$ a modulated signal which is zero when $v_{c}(t) \geq v_{r}(t)$ and one when $v_{c}(t)<v_{r}(t)$. Therefore, only two first-order differential equations (3) and (4) are required to fully describe the behavior of the system.

The output voltage of this circuit is generally periodic, as shown in Fig. 2. In this case, we used the components values first specified in Refs. 2 and 15, and obtained a $70 \mathrm{mV}$ ripple. Figure 3 represents the power spectrum of the output voltage $v(t)$ when the converter is governed by the control law $v_{c 0}(t)$ of Eq. (1). The spectrum has a peak at the switching frequency $1 / T$, with a magnitude of $250 \mathrm{~V}^{2} / \mathrm{Hz}$. For the electromagnetic compatibility compliance reasons, let us try to reduce the peak value of the spectrum while maintaining a small ripple. 


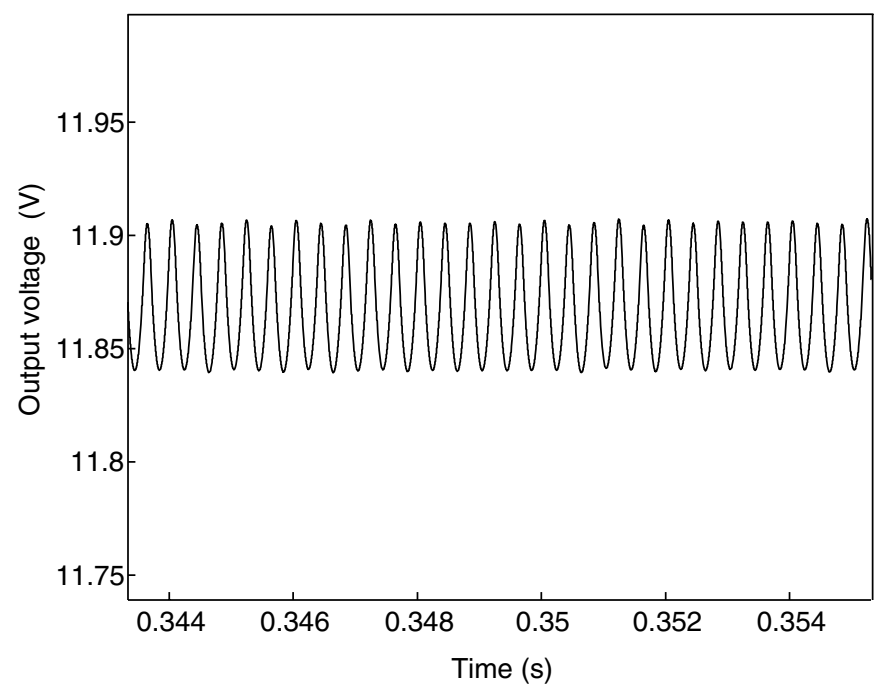

Fig. 2. The periodic output voltage $v(t)$ of the Buck converter with the control law $v_{c 0}(t)$ of Eq. (1) (70 $\mathrm{mV}$ ripple).

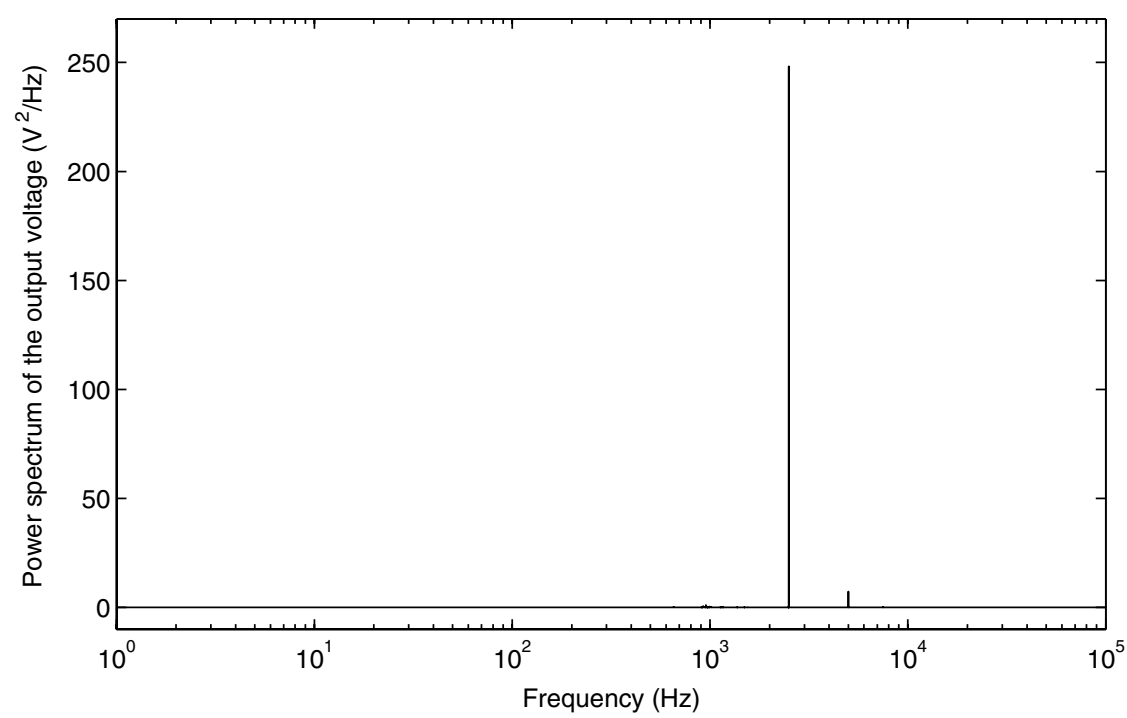

Fig. 3. Power spectrum of the output voltage $v(t)$ with the control law $v_{c 0}(t)$ of Eq. (1).

\section{Generating Chaos}

Purposely chaotifying a stable nonlinear system can be achieved by using the state feedback control with a small magnitude. ${ }^{11-13}$ The feedback control in Refs. 11 and 12 is a simple sinusoidal function of the system state. The new control law that 
we propose here has the expression

$$
v_{c}(t)=v_{c 1}(t)=u_{1}(t)+u_{2}(t),
$$

where $u_{1}(t)$ is defined in Eq. (1) and $u_{2}(t)$ is based on Ref. 11

$$
u_{2}(t)=c_{2} \sin \left[\omega_{2}\left(v(t)-V_{\text {ref }}\right)\right] .
$$

The anticontrol method of Ref. 11 considers the use of an additional nonlinear feedback controller $N C 1$, i.e., with switch $P$ of Fig. 1 in position 1 . The application of this method to switch-mode power supplies leads to a chaotic output voltage $v(t)$.

Varying the values of the parameters $c_{2}$ and $\omega_{2}$, we have observed that the optimum values of the ripple and of the maximum power spectrum magnitude are $200 \mathrm{mV}$ and $50 \mathrm{~V}^{2} / \mathrm{Hz}$ respectively. ${ }^{14}$

Even though many other spectral lines appear, the frequency-domain (spectral) performance is improved. References 7 and 8 also lead to the conclusion: unfortunately, the time-domain (ripple) performance is worsened because the output voltage ripple has increased, thus reducing the efficiency of the DC-DC converter.

One can wonder why we need to apply a method to generate chaos, when chaos is a phenomenon which can occur naturally in switch-mode power supplies. ${ }^{15}$ Indeed, these circuits exhibit chaos as parameters (like the input voltage $E$, the load resistance $R$, the inductance $L$ or the ramp period $T$ ) vary. The studied converter presents a chaotic behavior depending on the input voltage $E$ (when $E \geq 32.34 \mathrm{~V}){ }^{2,15,16}$ Figure 4 shows that the ripple is increased again $(\approx 1 \mathrm{~V})$ and therefore, another solution has to be found.

\section{Reducing the Output Voltage Ripple}

We introduce a new nonlinear controller $N C 2$, aiming at improving the power spectrum and ripple obtained with the previous control laws $v_{c 0}(t)$ and $v_{c 1}(t)$. We propose the following control law:

$$
v_{c}(t)=v_{c 2}(t)=u_{1}(t)+u_{3}(t),
$$

where

$$
u_{3}(t)=c_{3} v(t) \sin \left(\omega_{3} t\right)=c_{3} v(t) \sin \left(2 \pi f_{3} t\right) .
$$

This time, the expression (8) includes a multiplication of the state feedback with a sine. The amplitude and the frequency of the resulting signal $u_{3}(t)$ determine the number of times $S$ switches. If $f_{3}$ is much greater than the frequency $(1 / T)$ of the ramp generator, then $S$ switches many times during one period of the ramp, as shown in Fig. 5. In this case, the output voltage $v(t)$ does not have enough time to rise or to decrease too much, because of these multiple switches. Furthermore, the output voltage $v(t)$ is not sensitive to the variation of the initial conditions: the introduction of the nonlinear controller $N C 2$ determines a nonchaotic behavior of the converter. 


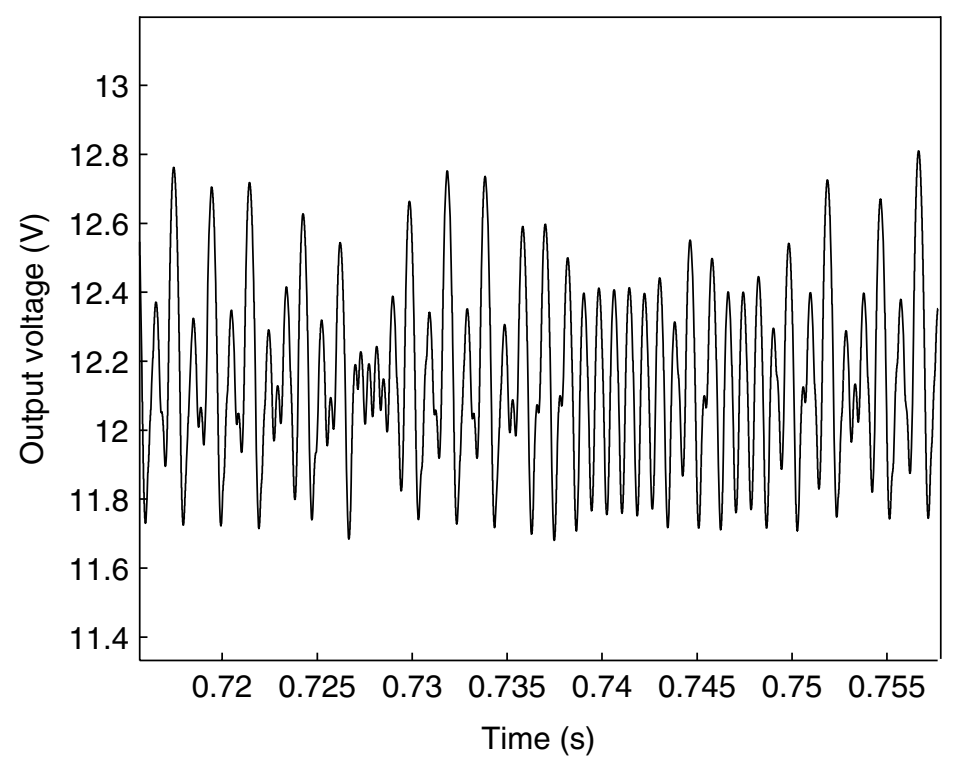

Fig. 4. The output voltage $v(t)$ of the Buck converter with the control law $v_{c 0}(t)$ of Eq. (1): chaotic behavior (1 $\mathrm{V}$ ripple).

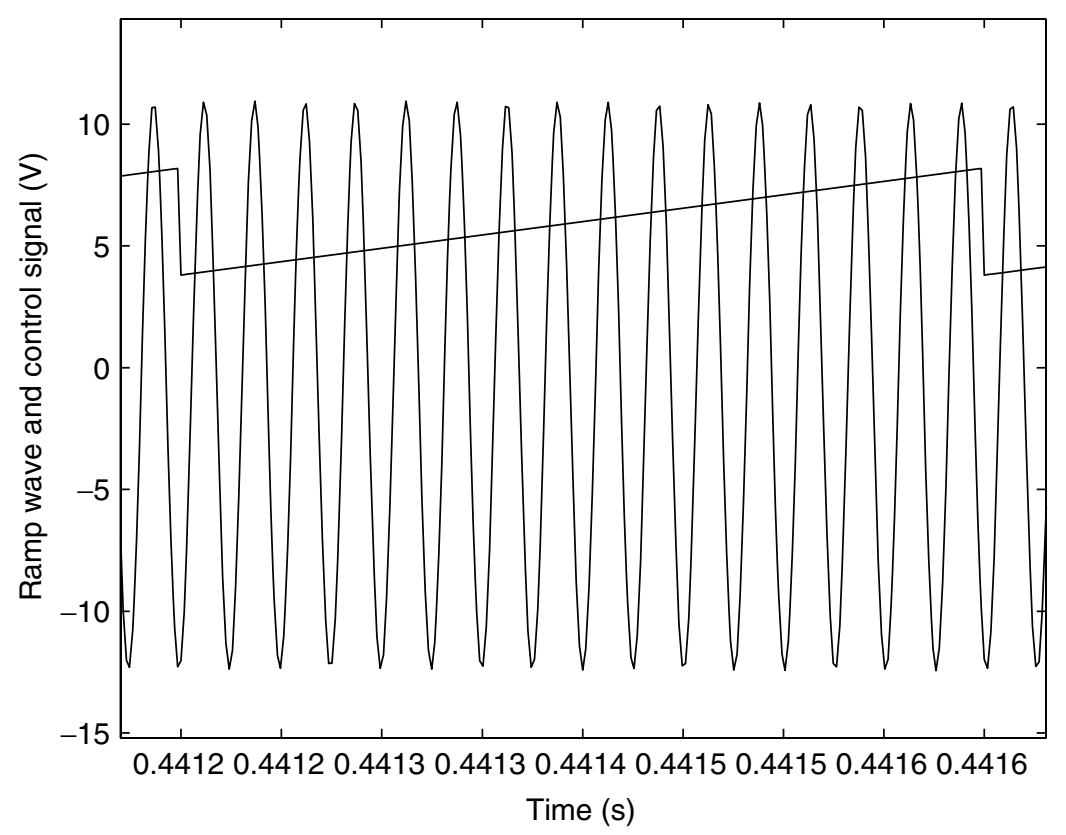

Fig. 5. Ramp wave $v_{r}(t)$ of Eq. (2) and control signal $v_{c 2}(t)$ of Eq. (7). 
Let us determine the angular frequency $\omega_{3}$ and the amplitude $c_{3}$, in order to find the best possible power spectrum and ripple. $\omega_{3}$ must be much greater than the angular frequency $(2 \pi / T)$ of the ramp generator, whereas the switching frequency of $S$ is limited to $[80 \mathrm{kHz}, 100 \mathrm{kHz}]$ in practice. Therefore,

$$
\frac{1}{T} \ll f_{3}=\frac{\omega_{3}}{2 \pi}<80 \mathrm{kHz} .
$$

Figure 6 shows that the ripple decreases rapidly for low values of $\omega_{3}$ and then stabilizes for higher values of $\omega_{3}$. Therefore, any $\omega_{3}$ in the domain $[200000 \mathrm{rad} / \mathrm{s}$, $500000 \mathrm{rad} / \mathrm{s}]$ is appropriate. This corresponds to the interval $[32 \mathrm{kHz}, 80 \mathrm{kHz}]$ for the frequency $f_{3}$ of $u_{3}(t)$. We chose $\omega_{3}=250000 \mathrm{rad} / \mathrm{s}\left(f_{3} \approx 40 \mathrm{kHz}\right)$.

The choice of the coefficient $c_{3}$ must be done to minimize the amplitude of the power spectrum. Figure 7 shows the power spectrum (obtained as the Fourier transform of the autocorrelation) of the output voltage $v(t)$, in function of $c_{3}$. The power contained in the peak of the switching frequency $1 / T$ decreases when $c_{3}$ increases, whereas lower frequencies give high amplitudes of the power spectrum. The minimum value of the power spectrum amplitude is obtained for $c_{3}=1.04$ : let us call it $\min (\operatorname{maxFFT})$. It represents the minimum of all the maxima of the power spectrum when $c_{3}$ varies.

Figure 8 presents the power spectrum of the output voltage $v(t)$, for $c_{3}=1.04$ and $\omega_{3}=250000 \mathrm{rad} / \mathrm{s}: \min (\operatorname{maxFFT})$ is equal to $3.77 \mathrm{~V}^{2} / \mathrm{Hz}$. We can observe that

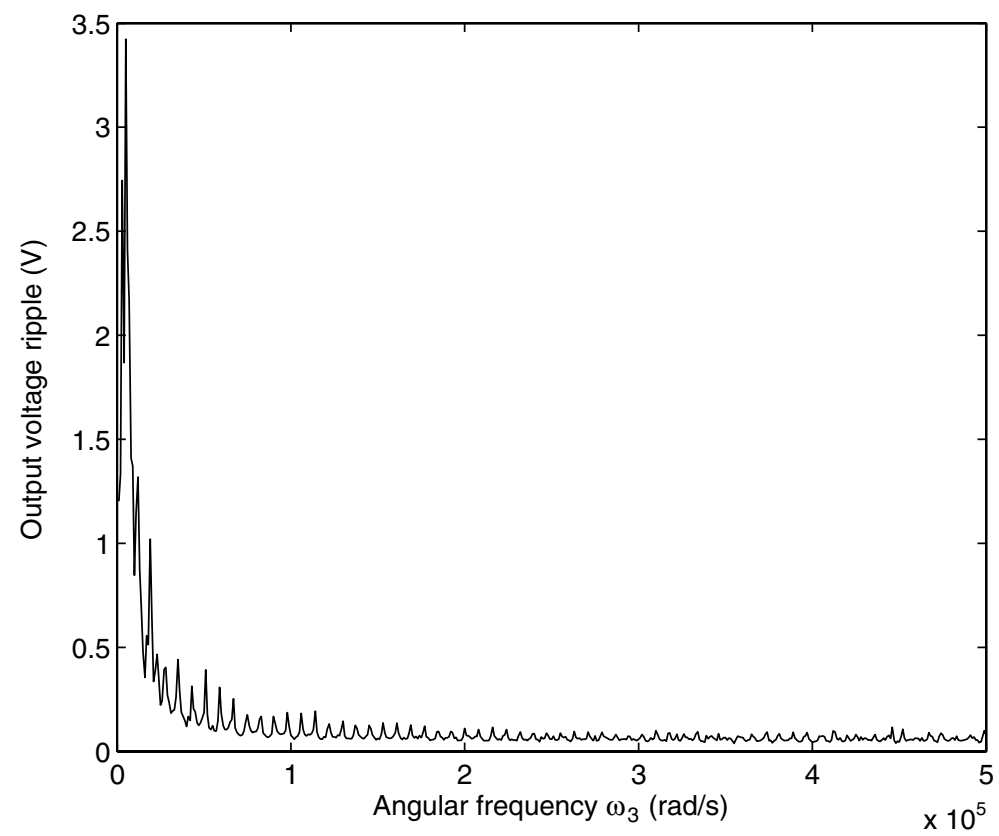

Fig. 6. Ripple of the output voltage $v(t)$ in function of $\omega_{3}$ (control law $v_{c 2}(t)$ of Eq. (7)). 


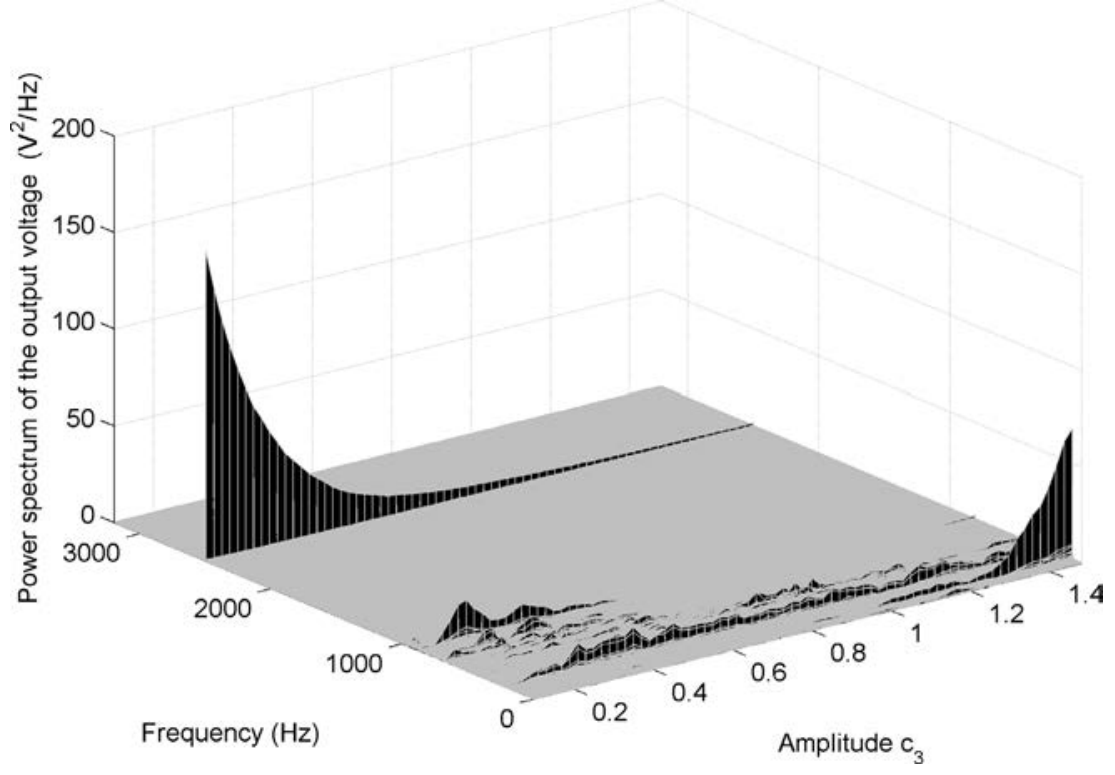

Fig. 7. Power spectrum of the output voltage $v(t)$ with the control law $v_{c 2}(t)$ of Eq. (7) ( $c_{3}$ as parameter).

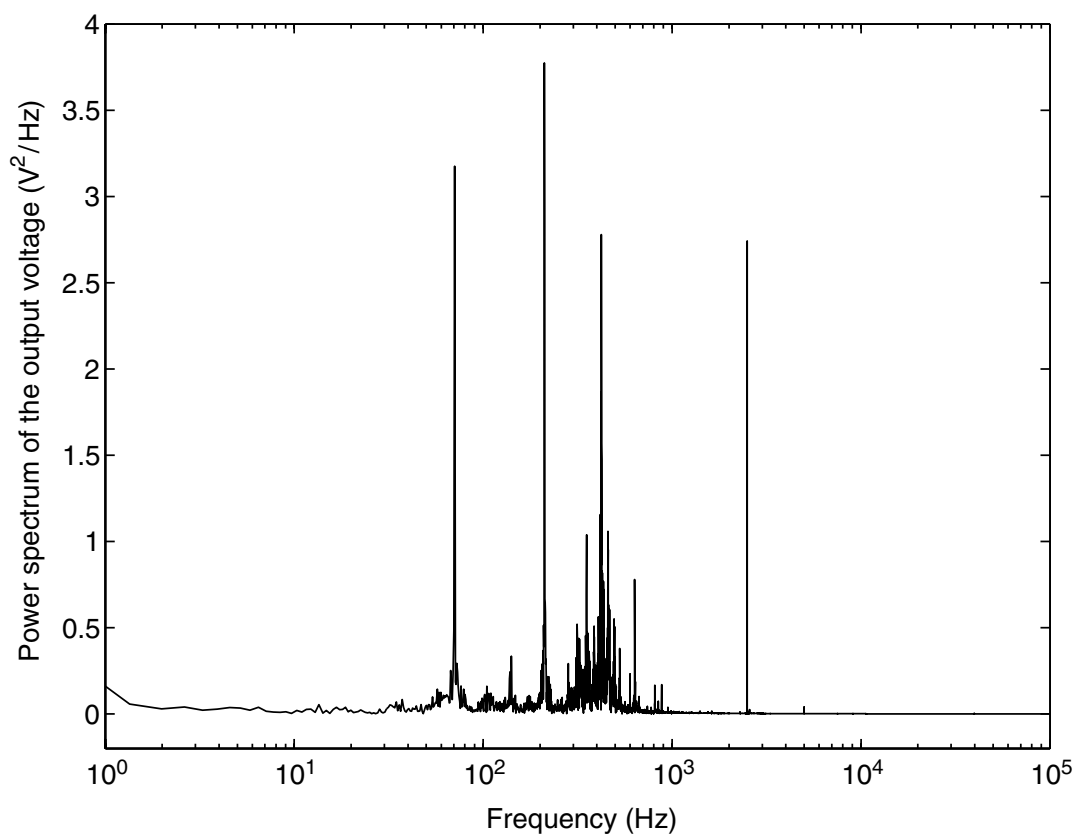

Fig. 8. Power spectrum of the output voltage $v(t)$ obtained for $c_{3}=1.04$ with the control law $v_{c 2}(t)$ of Eq. $(7)\left(\min (\operatorname{maxFFT})=3.77 \mathrm{~V}^{2} / \mathrm{Hz}\right)$. 
this spectrum is no more composed of a unique peak at the switching frequency $1 / T$ (or at its harmonics): many spectral lines appear at lower frequencies, therefore widening the band. Figure 9 finally presents the temporal representation of the output voltage $v(t)$ and shows that the ripple is $55 \mathrm{mV}$.

The various frequencies in the output voltage $v(t)$ arise from the very irregular form of $v(t)$ due to the intrinsic nonlinear dynamics driven by the on and off duration of the switch $S$ which varies during a period of the ramp, as shown in Fig. 5. On Fig. 9, a sequence is pointed out (inside the interval $1.435 \mathrm{~s}-1.44 \mathrm{~s}$ ) where the temporal representation of the output voltage $v(t)$ can be approximated by a sine. The period of $2.5 \mathrm{~ms}$ gives a $400 \mathrm{~Hz}$ peak on the power spectrum of $v(t)$. In the same way, the concentration of all the frequencies around $70 \mathrm{~Hz}-1 \mathrm{kHz}$ can be justified.

The $u_{3}(t)$ proposed here is introduced to maintain a small ripple of the output. Indeed, the two control laws $v_{c 0}(t)$ and $v_{c 2}(t)$ almost lead to the same ripple amplitude $(70 \mathrm{mV}$, respectively $55 \mathrm{mV}) \cdot u_{3}(t)$, as system feedback, is able at the same time to reduce the power contained in the peaks of the switching harmonics of the DC-DC converter. We can say that $v_{c 2}(t)$ has better performances than $v_{c 0}(t)$.

The new (nonchaotical) nonlinear feedback controller $\mathrm{NC} 2$ improves the frequency-domain (spectrum) performance, without deteriorating the time-domain (ripple) performance.

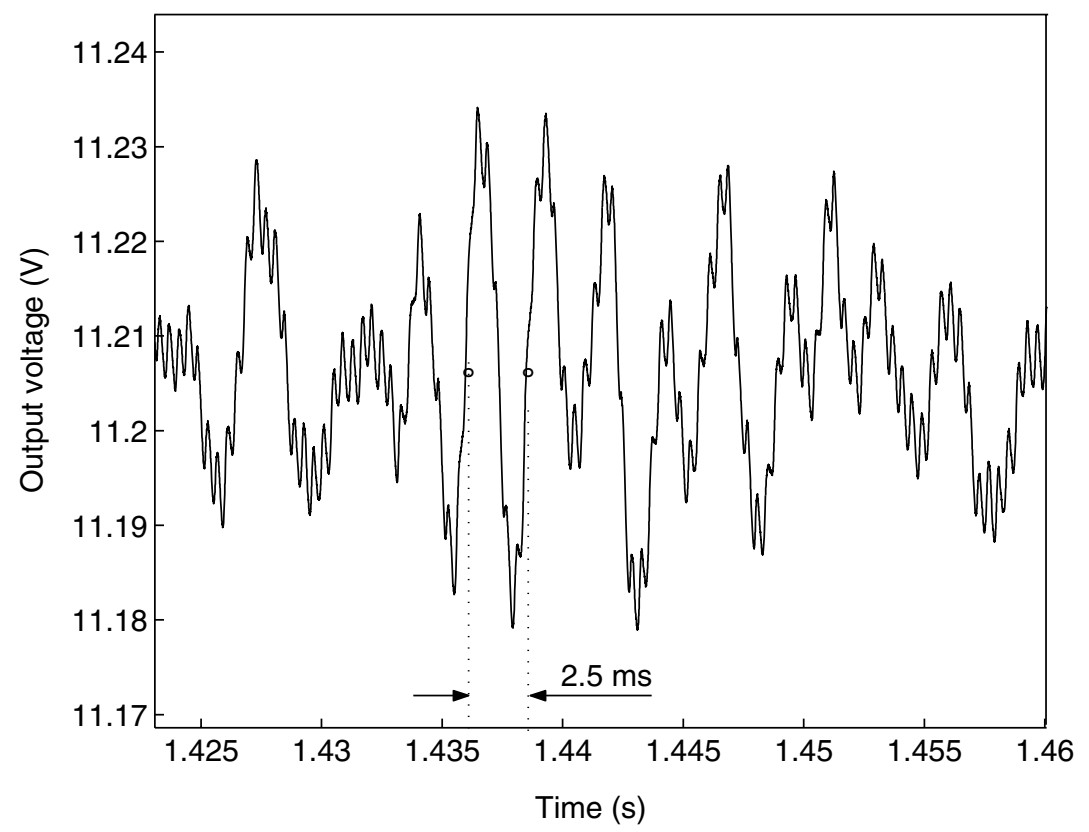

Fig. 9. Output voltage $v(t)$ obtained for $c_{3}=1.04$ with the control law $v_{c 2}(t)$ of Eq. (7) $(55 \mathrm{mV}$ ripple). 


\section{Generating Chaos and Reducing the Output Voltage Ripple}

With the controller $N C 2$, the Buck converter shows overall good performance but we want to investigate whether the introduction of chaos can improve the electromagnetic compatibility by further reducing spectral peaks. Therefore, we add the nonlinear controller $N C 1$. The control law becomes

$$
v_{c}(t)=v_{c 3}(t)=u_{1}(t)+u_{2}(t)+u_{3}(t) .
$$

The two controllers $N C 1$ and $N C 2$ use the same state variable (the output voltage $v(t))$ to provide the control laws $u_{2}(t)$ and $u_{3}(t)$. The parameters of $u_{3}(t)$ are chosen as in Sec. 4 . The choice of parameters $c_{2}$ and $\omega_{2}$ of $u_{2}(t)$ is done to minimize the power spectrum amplitude.

Figure 10 presents the maximum of the power spectrum amplitude (maxFFT) of the output voltage $v(t)$ for $0<c_{2}<1.4 \mathrm{~V}$ and $50 \mathrm{rad} / \mathrm{V}<\omega_{2}<550 \mathrm{rad} / \mathrm{V}$. Every maxFFT lower than $\min (\operatorname{maxFFT})$ obtained in the previous section $\left(3.77 \mathrm{~V}^{2} / \mathrm{Hz}\right)$ is represented with a black star $(*)$. The resulting black area is associated with $\omega_{2}$ and $c_{2}$ values for which the use of $v_{c 3}(t)$ is an improvement. The minimum value of all maxFFT is obtained for $c_{2}=0.1 \mathrm{~V}$ and $\omega_{2}=320 \mathrm{rad} / \mathrm{V}: \min (\operatorname{maxFFT})=$ $2.69 \mathrm{~V}^{2} / \mathrm{Hz}$. Using these values, we represent the power spectrum of the output voltage $v(t)$ and its time waveform in Figs. 11 and 12, respectively. These figures show that the output voltage ripple remains almost constant $(55 \mathrm{mV})$ when the control law $v_{c 2}(t)$ is replaced by $v_{c 3}(t)$ as feedback of the Buck converter. Therefore,

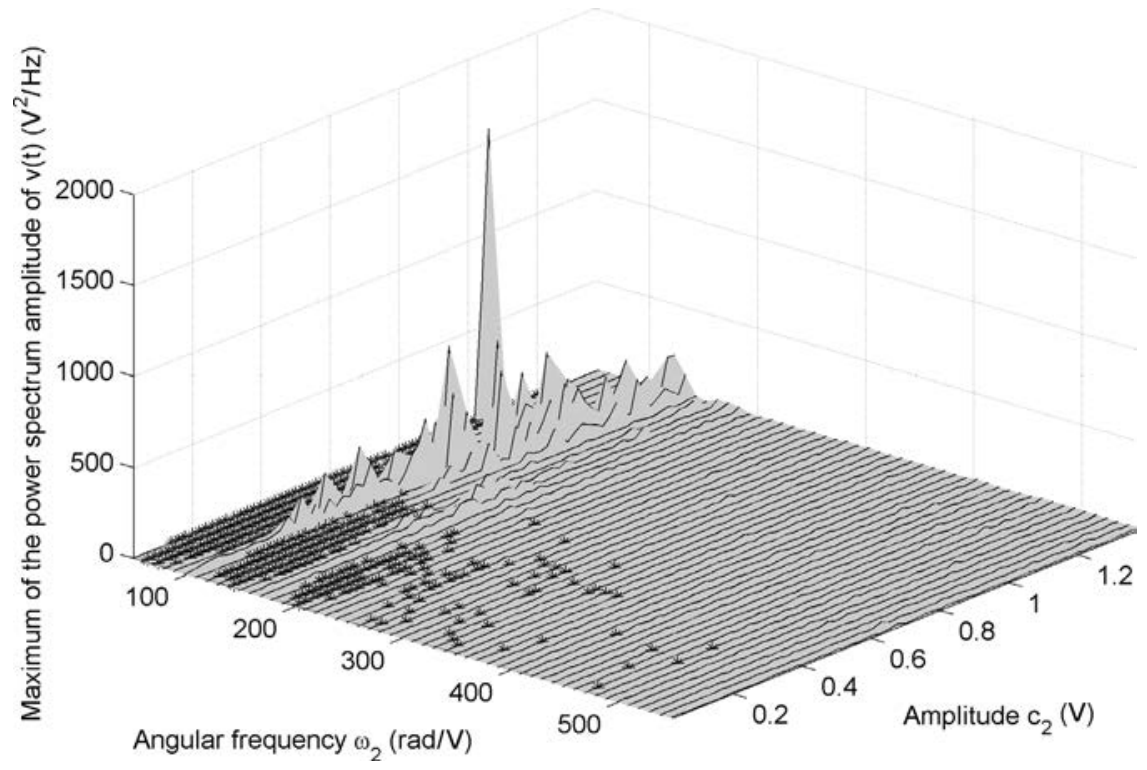

Fig. 10. The maximum of the power spectrum of the output voltage $v(t)$ with the control law $v_{c 3}(t)$ of Eq. (10) ( $c_{2}$ and $\omega_{2}$ as parameters). 


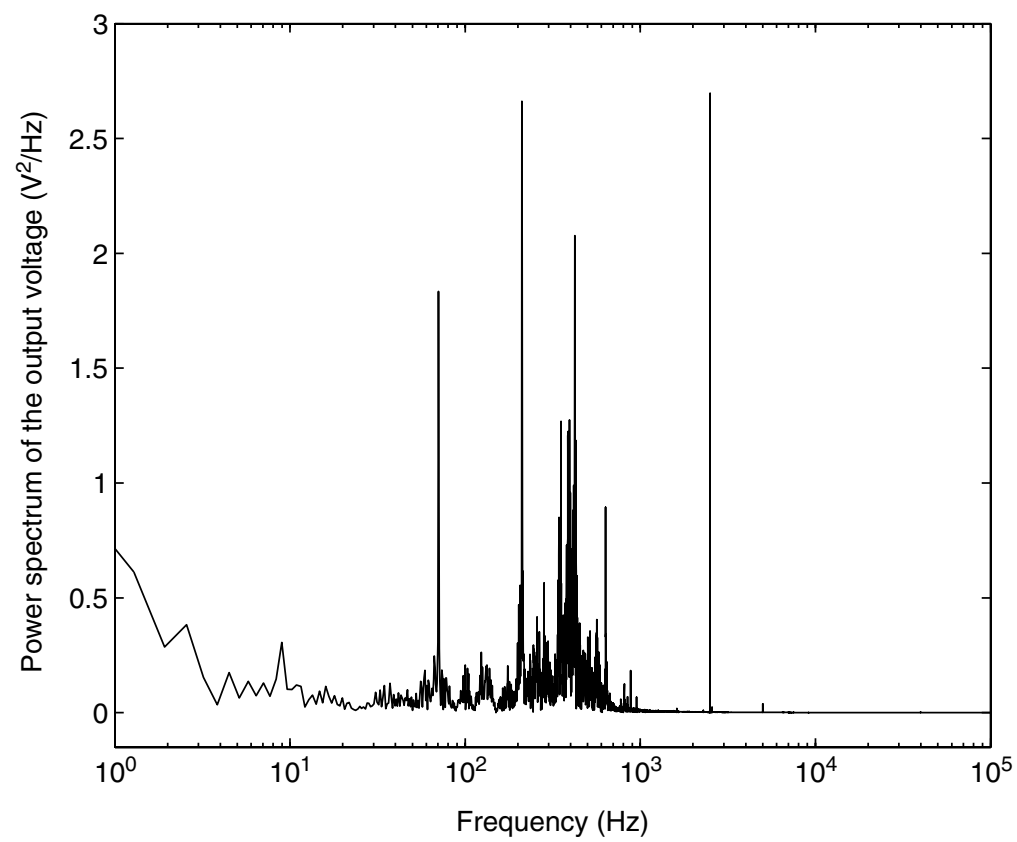

Fig. 11. Power spectrum of the output voltage $v(t)$ obtained with the control law $v_{c 3}(t)$ of Eq. (10), and with the parameters $c_{2}=0.1 \mathrm{~V}$ and $\omega_{2}=320 \mathrm{rad} / \mathrm{V}\left(\min (\operatorname{maxFFT})=2.69 \mathrm{~V}^{2} / \mathrm{Hz}\right)$.

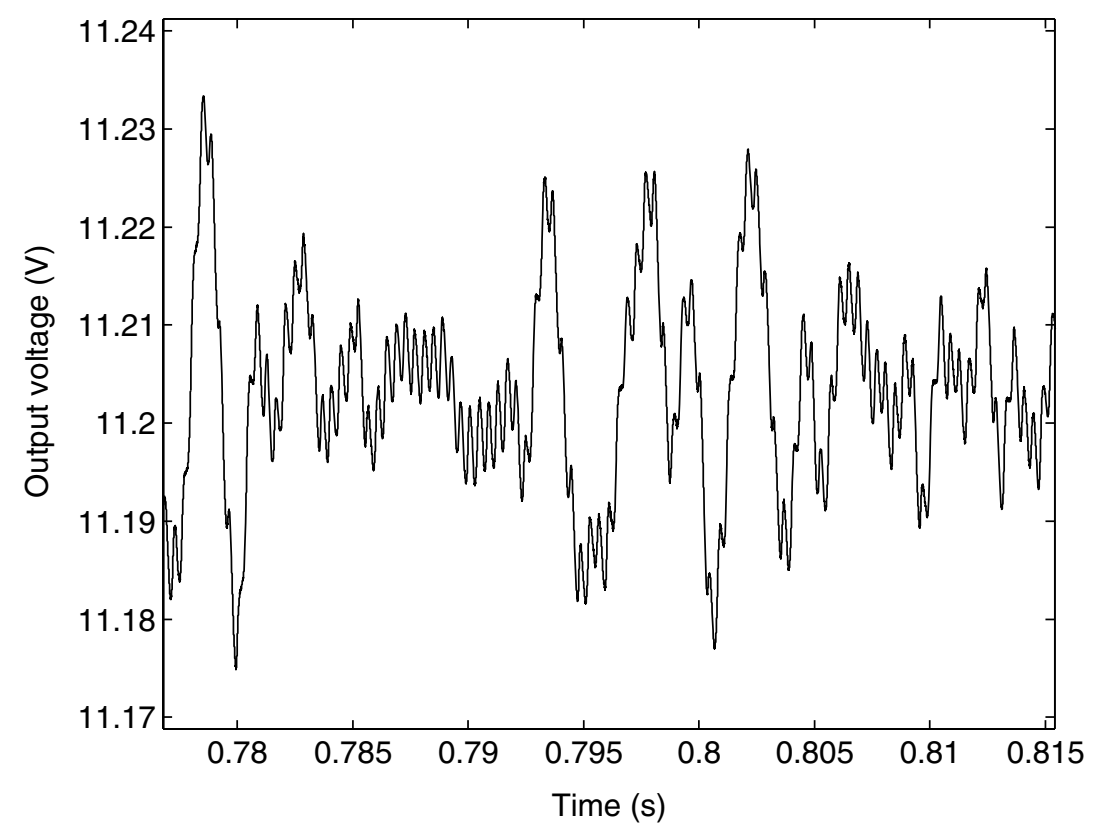

Fig. 12. Output voltage $v(t)$ obtained with the control law $v_{c 3}(t)$ of Eq. (10), and the parameters $c_{2}=0.1 \mathrm{~V}$ and $\omega_{2}=320 \mathrm{rad} / \mathrm{V}$ (55 $\mathrm{mV}$ ripple). 
Table 1. The performances of the converter with the control laws $\left(v_{c 0}, v_{c 1}, v_{c 2}, v_{c 3}\right)$.

\begin{tabular}{ccccc}
\hline $\begin{array}{c}\text { Control } \\
\text { law }\end{array}$ & $\begin{array}{c}\text { Maximum of power } \\
\text { spectrum }\left(\mathrm{V}^{2} / \mathrm{Hz}\right)\end{array}$ & $\begin{array}{c}\text { Ripple } \\
(\mathrm{mV})\end{array}$ & Chaos & $\begin{array}{c}\text { Wide } \\
\text { band }\end{array}$ \\
\hline$v_{c 0}$ & 250 & 70 & No & No \\
$v_{c 1}$ & 50 & 200 & Yes & Yes \\
$v_{c 2}$ & 3.77 & 55 & No & Yes \\
$v_{c 3}$ & 2.69 & 55 & Yes & Yes \\
\hline
\end{tabular}

the influence of $u_{2}(t)$ on the ripple is negligible. On the contrary, $u_{2}(t)$ decreases further the amplitude of the spectrum (from $3.77 \mathrm{~V}^{2} / \mathrm{Hz}$ to $2.69 \mathrm{~V}^{2} / \mathrm{Hz}$ ): $v_{c 3}(t$ ) has a better frequency-domain (spectral) performance than $v_{c 2}(t)$.

Table 1 summarizes the ripple and the power spectrum of the output voltage $v(t)$, using the four control laws $\left(v_{c 0}, v_{c 1}, v_{c 2}, v_{c 3}\right)$ as feedback. It shows that the power spectrum amplitude of the converter governed by the first control law $v_{c 0}(t)$ is reduced while the output voltage ripple is kept constant. The second control law $v_{c 1}(t)$ of Eq. (1) reduces the power contained in the peaks harmonics of the output voltage (down to five times), but leads to a large ripple. The control law $v_{c 2}(t)$ of Eq. (7) we propose ensures a good ripple and causes a spectacular decrease of the power spectrum amplitude. Finally, chaotifying the converter with the last control law $v_{c 3}(t)$ of Eq. (10) leads to a higher power spectrum amplitude decrease.

Of course, the reduction of the maximum of the power spectrum (Fig. (3)) of $v(t)$ can be achieved by increasing the basic switching frequency $1 / T$ of the converter governed by the control law $v_{c 0}(t)$. Then, the control law $v_{c 0}(t)$ gives similar results as $v_{c 3(t)}$ if the generator ramp frequency of the converter is $f_{3}$. This classical method has few properties; this justifies the use of chaos.

Chaos is a very interesting nonlinear phenomenon, which has been intensively studied during the three last decades. Chaotification is theoretically attractive and yet technically very challenging, since it involves generating abundant and complex dynamical behaviors. The understanding of chaotic behavior opens up new possibilities of operating regimes that can help to optimize design. Chaos provides a system designer with a variety of special properties, richness of flexibility and a multitude of opportunities.

The target of the paper is to show that chaos reduces the maximum of power spectrum. But chaos, either occurring naturally or purposely created, increases the output voltage ripple. This is why we introduce chaos in the converter only after an increase of the switching frequency (with the control law $v_{c 3}(t)$ ), which reduces the output voltage ripple.

\section{Conclusion}

The purpose of this paper is to introduce an original method of chaos generation in switching systems in general and power electronic circuits in particular. 
Indeed, applying chaos anticontrol (i.e., with a nonlinear feedback controller $N C 1$ ) to switch-mode power supplies improves the frequency-domain (spectrum) performance while the time-domain (ripple) performance degrades. Our method consists in designing a new nonlinear controller $(N C 2)$ which maintains a small ripple in the output and which is able at the same time to achieve low spectral emission. The parameters of this controller are chosen in order to have a power spectrum improvement of the output voltage. Finally, the combination of our method $(N C 2)$ with the standard anticontrol method $(N C 1)$ reduces even more the power contained in the spectral lines, without deteriorating the output voltage ripple. We are currently working on a closed-form iterative-map, which describes the behavior of the controlled Buck converter. This map is useful to reduce the computing time for the numerical simulation and represents an approach to the theoretical analysis.

\section{References}

1. H. Koizumi, I. Sasase and S. Mori, Analysis of class D-E resonant DC-DC converter using thinned-out method, J. Circuits Syst. Comput. 11 (2002) 35-50.

2. M. di Bernardo, F. Garofalo, L. Glielmo and F. M. J. Vasca, Switchings, bifurcations, and chaos in DC-DC converters, IEEE Trans. Circuits Syst. I: Fund. Theor. Appl. 45 (1998) 133-141.

3. Y. M. Lai, C. K. Tse and P. Mehta, A symbolic circuit modeling program for DC-DC power converter circuits, J. Circuits Syst. Comput. 8 (1998) 329-335.

4. J. H. B. Deane, P. Ashwin, D. C. Hamill and D. J. Jefferies, Calculation of the periodic spectral components in a chaotic DC-DC converter, IEEE Trans. Circuits Syst. I: Fund. Theor. Appl. 46 (1999) 1313-1319.

5. F. L. Lin and D. Y. Chen, Reduction of power supply EMI emission by switching frequency modulation, IEEE Trans. Power Electron. 9 (1994) 132-137.

6. A. M. Stankovic, G. C. Verghese and D. J. Perreault, Analysis and synthesis of randomized modulation schemes for power converters, IEEE Trans. Power Electron. 10 (1995) 680-693.

7. O. Woywode, H. Guldner, A. L. Baranovski and W. Schwarz, Bifurcation and statistical analysis of DC-DC converters, IEEE Trans. Circuits Syst. I: Fund. Theor. Appl. 50 (2003) 1072-1080.

8. W. C. Y. Chan and C. K. Tse, Study of bifurcations in current-programmed DC-DC Boost converters: From quasi-periodicity to period-doubling, IEEE Trans. Circuits Syst. I: Fund. Theor. Appl. 47 (1997) 1129-1142.

9. V. In, S. E. Mann, W. L. Ditto and M. L. Spano, Experimental maintainance of chaos, Phys. Rev. Lett. 74 (1995) 4420-4423.

10. H. Cao, X. Chi and G. Chen, Suppressing or inducing chaos in a model of robot arms and mechanical manipulators, J. Sound Vibration 271 (2003) 705-724.

11. X. F. Wang and G. Chen, Chaotifying a stable map via smooth small-amplitude high-frequency feedback control, Int. J. Circuit Theor. Appl. 28 (2000) 305-312.

12. X. F. Wang, G. Chen and K. F. Man, Making a continuous-time minimum-phase system chaotic by using time-delay feedback, IEEE Trans. Circuits Syst. I: Fund. Theor. Appl. 48 (2001) 641-645.

13. G. Chen and D. Lai, Making a dynamical system chaotic: Feedback control of Lyapunov exponents for discrete-time dynamical systems, IEEE Trans. Circuits Syst. I: Fund. Theor. Appl. 44 (1997) 250-253. 
14. C. Morel, M. Bourcerie and F. Chapeau-Blondeau, Extension of chaos anticontrol applied to the improvement of switch-mode power supply electromagnetic compatibility, Proc. IEEE Int. Symp. Industrial Electronics ISIE'04, Ajaccio, France, May 2004, pp. 447-452.

15. E. Fossas and G. Olivar, Study of chaos in the Buck converter, IEEE Trans. Circuits Syst. I: Fund. Theor. Appl. 43 (1996) 13-25.

16. D. C. Hamill, J. H. B. Deane and D. J. Jefferies, Modeling of chaotic DC-DC converters by iterated nonlinear mappings, IEEE Trans. Circuits Syst. I: Fund. Theor. Appl. 7 (1992) 25-36. 